\title{
A case study of capitalisation and valorisation of our technical heritage
}

\author{
F.Laroche ${ }^{1}$, J.-L.Kerouanton ${ }^{2}$, A.Bernard ${ }^{3}$ \\ ${ }^{1}$ IRCCyN, Ecole Centrale de Nantes, 1 rue de la noë, 44000 Nantes, France \\ florent.laroche@irccyn.ec-nantes.fr \\ ${ }^{2}$ Centre François Viète, Université de Nantes, Fac de sciences, 44000 Nantes, France \\ jean-louis.kerouanton@univ-nantes.fr \\ ${ }^{3}$ IRCCyN, Ecole Centrale de Nantes, 1 rue de la noë, 44000 Nantes, France \\ alain.bernard@irccyn.ec-nantes.fr
}

\begin{abstract}
For the 2008 CIRP Design conference, we have presented a scientific article dealing with a new way of thinking our technical heritage: we would like to preserve it as a digital object.

Project deals with a physical mock-up of Nantes city built in 1899 and used for the Universal exposition in France in 1900 in Paris. The heritage object is nowadays in the museum but exposed as a fish inside an aquarium. Thanks to a virtual system coupling a tactile screen with semantic research modules, 3D active screen and light pointer, it will allow the visitor to better understand the mock-up and emphasize important places of Nantes city life.

However it does not mean beautiful 3D animation with nice static rendering; indeed, we create virtual mockups which are dynamically operating. We use CAD software and engineering simulation tools. Nowadays the global methodology has been improved: it is named Advanced Industrial Archaeology. In this communication, we will detail a new experimentation done in partnership with a French museum: the Château des Ducs de Bretagne in France. This project deals with a physical mock-up of Nantes city built in 1899 and exposed in 1900 for the World Fair that took place in Paris, France. The heritage object is nowadays in the museum but exposed as "a fish inside an aquarium". Thanks to a virtual system coupling a tactile screen with semantic research modules, a 3D active screen and a light pointer, it will allow the visitor to better understand the mock-up and emphasize important places of the city. The mock-up represents our industrial heritage with old shipyards of Nantes.
\end{abstract}

\section{Keywords:}

Knowledge data base, Virtual Reality, 3D digitalisation, industrial heritage, socio-economic, Museum, Nantes

\section{INTRODUCTION AND CONTEXT}

Industrial archaeology is one specialty of archaeology. This discipline also study material remaining from the past but it focus more specifically on industrial heritage as: mining equipment, metallurgical and manufacturing plants, road, bridges, tunnels, railways, marine, waterways, aeronautic... Industrial archaeology is born in England in year 1940 with the first studies of the industrial revolution. However the industrial heritage is not so widely known, indicating a latent disinterest of our society for our industry.

Since 2004, our research team works to establish a new discipline: Advanced Industrial Archaeology (AIA). The term "Advanced" is the same extension as used by mechanical domain when dealing, for example about "Advanced CAD" where it suggests the use of new kind of specialized software for creating more complex surface or parameterized parts...

For the CIRP General Assembly in 2007, we have made a communication about the impact of 3D numerical devices and environments when redesigning and valorising mechanical systems [1]].
The main idea developed in this paper deals with the use of virtual technologies for heritage. But, when we speak about heritage, there are not only architecture or castles as the architects Houdin and Dassault System have demonstrated it using Catia V5 for understanding the Cheops pyramid [2]. Indeed, objects studied by our research team belong to scientific and/or technical domains. Machines, industries and socio-economical context are also very important for a better understanding of our history. Our proposition consists in overturning the time axis of the design process generally used for developing contemporary technical products. That means that we begin at the end of machine lifetime and come back to the initial need that define why the technical object had been created.

This global process is the core of what we call Advanced Industrial Archaeology:

1 First step is the digitalization of the physical object and the capitalization of the know-how learnt by studding the machine.

2 Next, thanks to virtual reality technologies, we can valorise this amount of knowledge. 


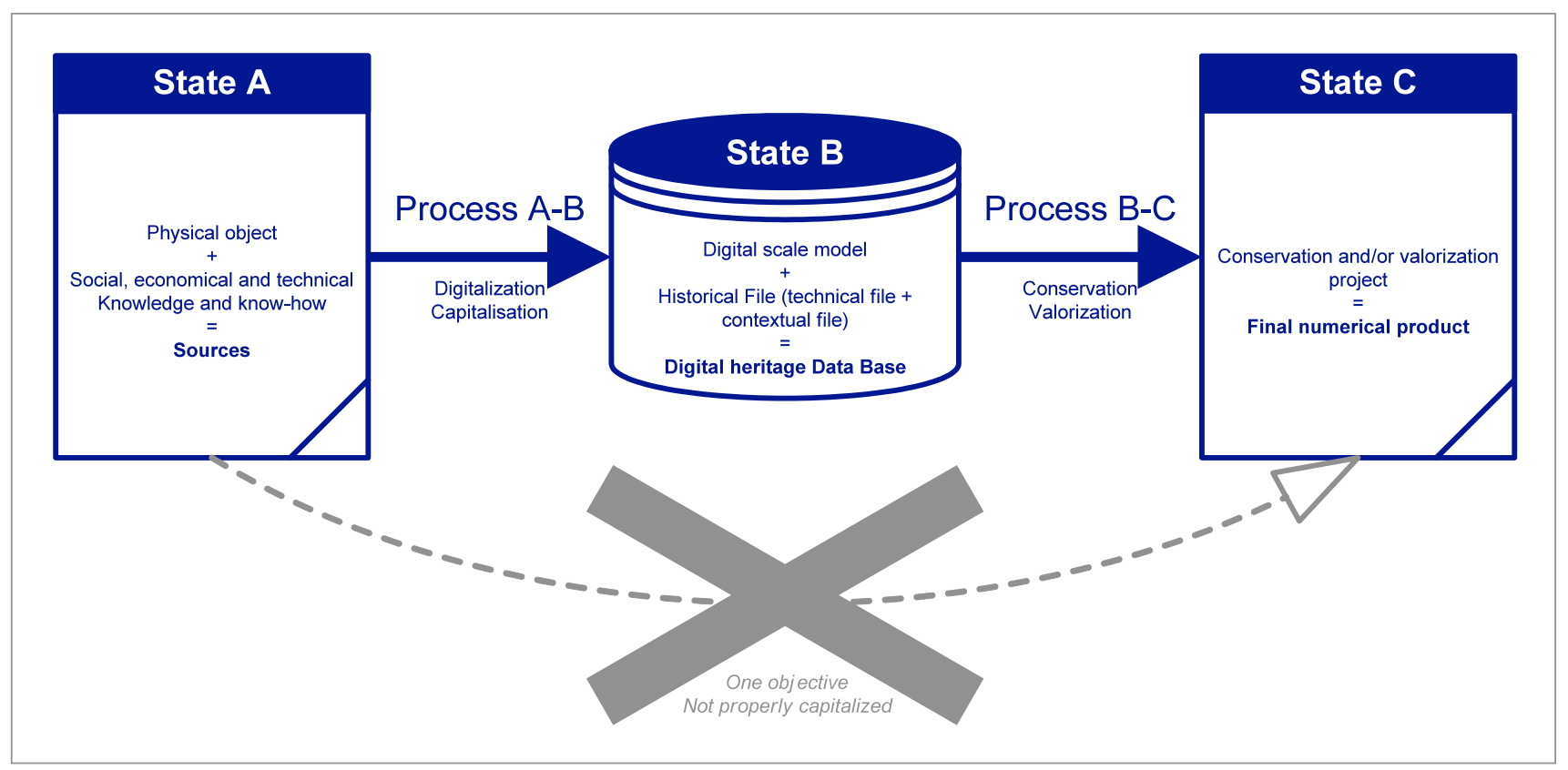

Figure 1 :General methodology to preserve and enhance the technical and industrial heritage

Nowadays, the methodology to design an old technical object has been validated and experimented on several case studies: capitalize $\rightarrow$ formalize $\rightarrow$ valorise.

For this new edition of the CIRP Design, we would like to go further with the AIA adventure. We would like to demonstrate it also can be used to capitalize industrial sites and not only machines [3]. In this article, at first we will give basis about the general methodology where an information model will drives the heritage conservation process. Next, we will report a project started in September 2008, which should finished in 2011. It is done in partnership with the History Museum of Nantes (the Château des Ducs de Bretagne, department 44, France).

One specificity of this project and consequently one most difficulty is the fact that it is a pedagogical project. That means that students do all works. Indeed, it is one scientific hypothesis: we would like to renew the link between history, technique and culture. Then, efforts must be done for:

- Assuming prolongation of works,

- Having a global process overview,

- Allowing continuous knowledge.

Therefore, our students have written major part of the second part of this scientific article. It represents more than 12 teams; approximately 60 students since 2008 . Consequently, they are all associated as co-authors for having participated in writing this article (see acknowledgements at the end).

\section{BACKGROUND: SCIENTIFIC BASIS}

As described in our previous article in the CIRP Design conference [4], the AIA methodology of reverse engineering proposes 3 stages (Figure 1).

One advantage of introducing the state $B$ is to have the possibility of numerous finalities. In fact, going directly from state $A$ to state $C$ is not recommended. The various possibilities of final numerical product of state $\mathrm{C}$ (thesaurus virtual use for teaching or academic experts, reconstruction, museum valorisation...) show that it is necessary to capitalize a maximum amount of knowledge at the beginning of the heritage preservation project. Then, an intermediate structure containing all information, data and knowledge is required. It is a new virtual document that informs the heritage object. It is constituted of a virtual database allowing organising the knowledge involved. It is what we called the Digital Heritage Reference Model (DHRM).

This intermediate state $B$ is more than a simple database. It must be able to support:

- past information of a specific object,

- contemporary information of the same object,

- relations between those two information past and present.

Last condition is very complicated to implement into a computer system. But, thanks to the use case detailed later in the article, new scientific hypotheses has been solved using a meta-model.

\section{INFORMATION MODEL: INTERMEDIARY REPRESENTATION OF DESIGN MODEL}

Thus, we consider the heritage object studied as an object with several intermediate states. Evolution of those states is framed by a time axis unrolling the patrimonial process.

Figure 2 shows the four intermediary representation states and the three actions requires by the general methodology.

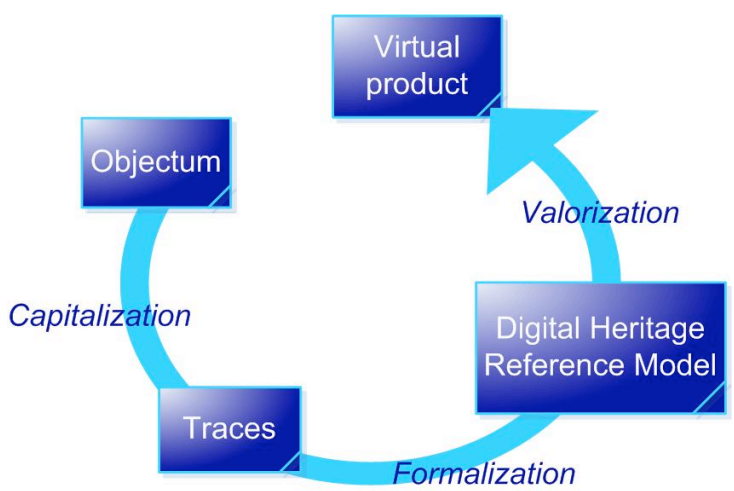

Figure 2: Object transformation: different intermediary states 


\begin{tabular}{|c|c|c|c|c|c|}
\hline \multicolumn{2}{|r|}{ Step } & Action & State & \multicolumn{2}{|c|}{ Concetpual object manipulated } \\
\hline 0 & & & Objectum & Vestiges & Records \\
\hline 2 & $\begin{array}{l}\text { InterprEtation / Formalization } \\
\text { / Design / Storage }\end{array}$ & $\begin{array}{l}\text { Advanced Industrial } \\
\text { Archaeology }\end{array}$ & $\begin{array}{c}\text { Digital Heritage } \\
\text { Reference Model }\end{array}$ & Digital Mock-up & Knowledge \\
\hline
\end{tabular}

Figure 3: Items handled during the digital heritage process

Indeed, all the intermediary objects use the same representation model. For each step of the digital heritage process, figure 3 shows:

- What have to be done (= action)

- Which state is the intermediary object

- What compound it (3D physical parts and/or documents)

Figure 4 gives an overview of the information system that drives the heritage process. The UML model details how the database can be constituted. This database is the main core of the DHRM. We can distinguish:

\subsection{The "objectum":}

Why this object is beautiful? Why we like it? Why we do not like it? "Objectum" is the starting point of the heritage process. Indeed, when an object is going to disappear, many people are desperate to save it. What is the purpose? No answer can be provided and no one knows how to explain it but everyone agrees that the object must be preserved. Indeed, it is a feeling; it gives us emotion. The dictionary would say: «Objectum is something that affects senses ». According to UNESCO point of view, an object must be conserved if it has:

- an aesthetic value

- an historical value

- and so it has an exceptional significance at the world level

\subsection{The "traces" of the object:}

- "Traces". First step concerns data acquisition. We have to capture all physical information of the studied object and to capitalize all knowledge and know-how: socio-economic, technical and industry context... it is what we call a "trace". We can use Knowledge Management methods and tools that are commonly used by contemporary enterprises [5].

- "Vestiges". As sometimes the object falls done, it remains only "pieces" that compound "vestiges". For acquiring "vestiges", we can use for example callipers. Moreover, 3D scanning tools can sometimes be used in order to have more information, to capture more complex surfaces or if we are in a hurry of an object that is going to disappear or to be destroyed [6].

\subsection{The Digital Heritage Reference Model:}

- "Knowledge". Implicit and explicit data have been collected; it is now necessary to organize, study and inter-connect them. Consequently, there is a transformation of the sub-class "sources" into a new UML class of equivalence: "knowledge".

- "Digital mock-up". The technical understanding phase allow using the 3D data. Main objective consists in designing a complete 3D digital model. In order to have a precise model, we use engineering software tools probing that the model are scientifically realistic [7]. However, 3D scan is not enough for the global comprehension and the object must be contextualized. External knowledge and anthropological investigations are therefore correlated with the $3 \mathrm{D}$ cloud of points and, at the end of the study; an operating digital mock-up is designed. Then "sources" allow validating the DMU (= Digital Mock-Up).

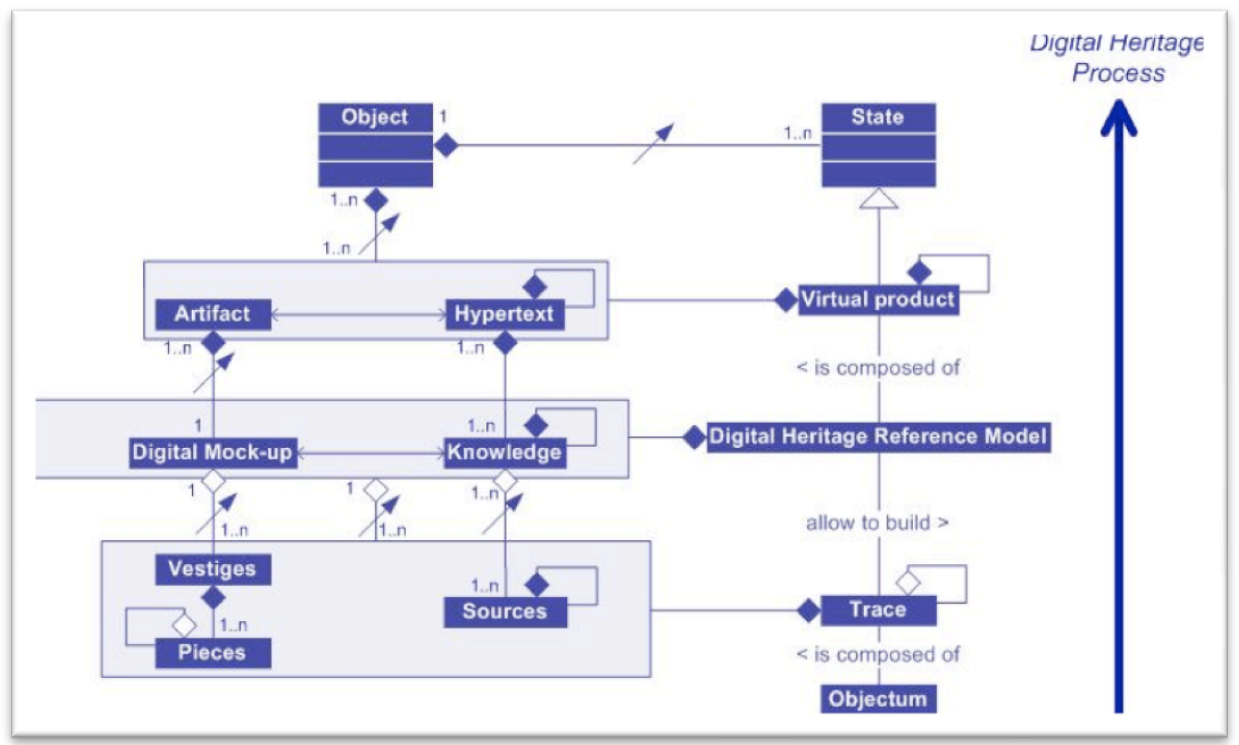

Figure 4: Ontology describing conceptual objects manipulated 


\subsection{Virtual product for museum valorisation}

- "Artifact". The term is widely used by museum curators. It is one representation of the object. It can be one part of the object, as sometimes the original object does not exist in its original condition.

- "Hypertext". This conceptual class explains the surrounding of the object. It allows giving back the accumulated data and knowledge produced. In a museum, the hypertext will replace the labels put near an object for explaining it. But as labels must be no longer than 50 words, it is a real difficulty to choose if we put a simple caption, a description of the subject, or tell a story...? It is so restrictive of the amount of knowledge accumulated that digital way will be the solution. It available to access the entire corpus description of the object.

\section{NANTES1900 PROJECT EXPERIMENTATION}

Thanks to the scientific work explained before we are developing a project in partnership with the Museum of Nantes in France. One of the objectives consists to create the Digital Heritage Reference Model for the Museum. As it is an experience, if it succeeds, we hope to extend our proposition to numerous museums and also to propose it to French culture ministry in order to use it as the new reference model for capitalizing our heritage.

Notice that every student teams of the project have written following paragraphs of this communication. We have made some links between the different parts but no more in order to keep their original texts. Please, accept our excuses if you meet big mistakes.

\subsection{Context of the project and definition of the heritage object studied}

Since the beginning, the city of Nantes (France) has always been a powerful harbour of the Atlantic sea. In order to demonstrate its power, the Chamber of Commerce of the city decided to order a mock-up of the harbour. It was established for the "World Fair Exposition" of 1900 in Paris. Later, it has been updated until the First World War. After the conflict, the Chamber of Commerce gave it to the Nantes City Museum (the Museum of Salorges). Nowadays, it is classified as a heritage object of the municipal collections. It is installed in the permanent exhibition of the Musée du Château des Ducs de Bretagne.

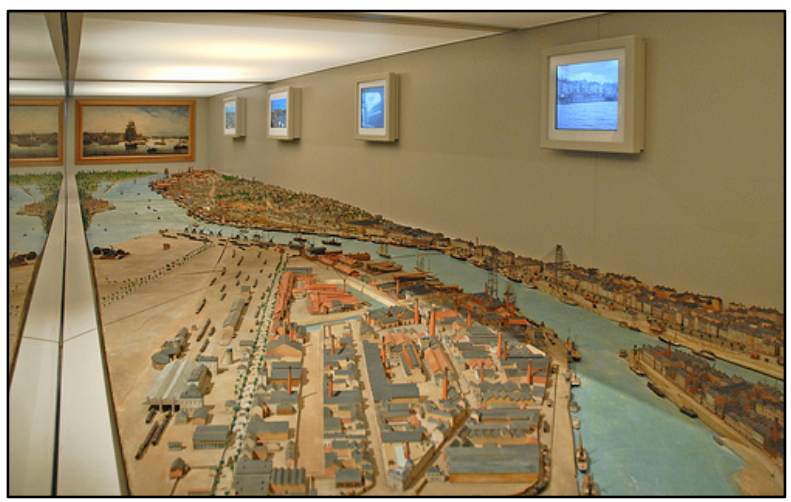

Figure 5: The physical mock-up inside its "aquarium"
The mock-up measures 9.2 meters long and 1.85 meters large. Paul Duchesne has built it in 1899. The scale is $1 / 450$ (so as to have a comparison reference: streetlights stick have a diameter of $1 \mathrm{~mm}$ inside the mock-up). The full mock-up represents approximately $3.44 \mathrm{~km}^{2}$ of Nantes city harbour.

Recently, the Museum decided that this Nantes harbour mock-up must "speak". Thus, a partnership was established between the museum and Nantes school institutions (Ecole Centrale, University...) in order to model it and propose an innovative form of valorisation.

The digital modelling of this mock-up allows historical analysis of the industrial situation at the beginning of the $\mathrm{XXe}$ century. For example, the harbour can be considered as a prolongation of the old city. Beyond of a simple "photography" in three dimensions done by 3D scanners, there is a real problematic of interoperability between topographic data and documentary information. This knowledge can help to understand the circulation and exchange flows of the industrial landscape. [8]

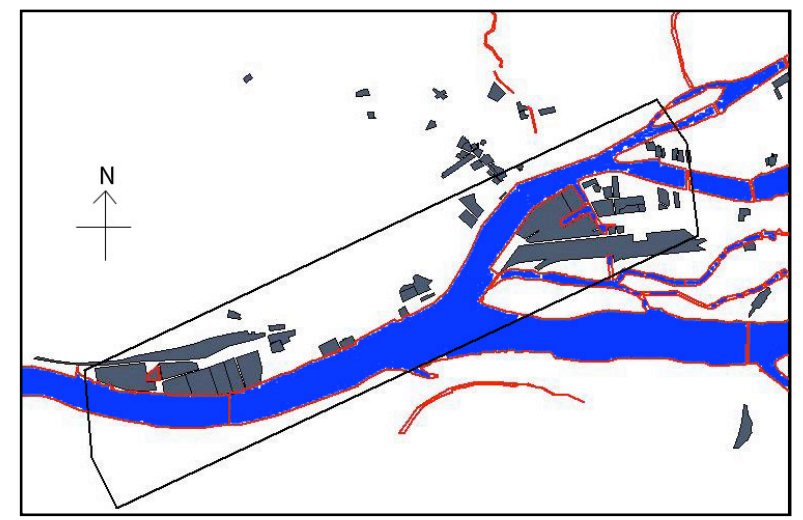

Figure 6: Borders of the mock-up on a SIG map

\subsection{Objectives and main steps: innovation as a keyword!}

The project purpose is to develop an interactive system between the visitor, the Internet, the physical model and the database associated to the virtual representation of the heritage object. The public presentation should be innovative, easy to use and educational. The device will allow combining an Augmented Reality system inside the museum room so that every visitor can access the knowledge (it is an in vivo system). Moreover, the system will allow valorising the accumulation of historical knowledge for a wide distribution, access to libraries or on the Internet; mainly targeted to students and researchers.

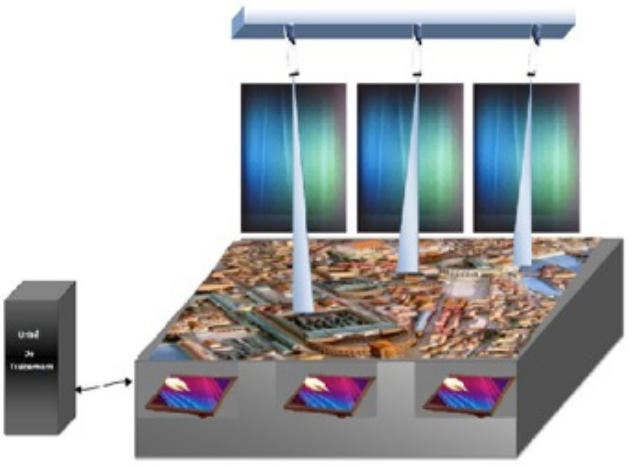

Figure 7: Illustration of the future virtual reality system 
Main aspect concerns the creation of the Digital Heritage Reference Model database that will support the knowledge. It will include a 3D scanned model and a compilation of the artefact' knowledge. The data management system will support heterogeneous format (text, image, sound, videos...) and will propose a semantic indexer/researcher.

\subsection{Museum constraints: multimedia / Opensource}

Notice that one most important constraint is that the system will be Open source (Museum technology choice) in order to permit evolution and upgrade of the knowledge base. Our project will also respect the museum policy: valorising heritage collections by NTIC media. Educational and fun as the same time, those facilities enrich and enlighten the museum and can reach a wider audience.

16 kiosks and over 24 broadcast stations, archives, sound clips, movies (including real-time 3D reconstruction of Nantes in 1756), and $180^{\circ}$ immersive projection have been selected and developed by the Museum. Nantes 1900 project is a new one that will continue efforts done until nowadays. An operating prototype will be delivered and tested inside the museum in July 2010.

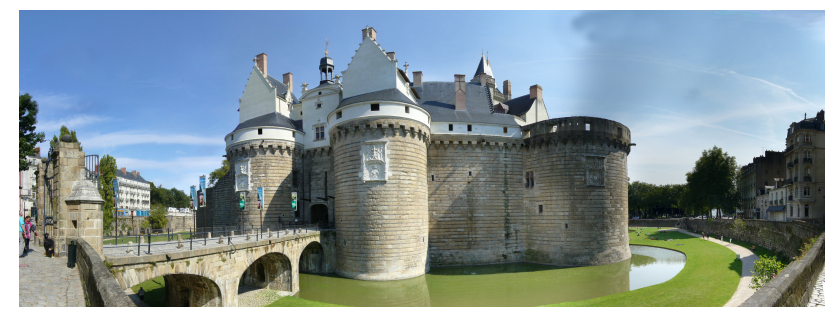

Figure 8: The Chateau des Ducs de Bretagne

\subsection{Inter-disciplinarity competencies: a university project}

This project is a multi-field and transversal experiment requiring numerous competences:

- Social and human sciences for the technical and industrial history, memories \& heritage, geographical analyses, heritage and museography...

- Engineering sciences for 3D scanning, mechanical design, mathematical computation, informatics database, virtual reality development...

Notice that the mechanical team works on the DMU (Digital Mock-Up). After the digitalization, they are trying to automate the 3D mesh simplification and the colorization of the cloud of points.

Due to the duality between engineering domain and social domain, Nantes1900 project is a new challenge: team is heterogeneous in terms of vocabulary, method of work, issue or area of expertise...

One more originality of the project lies to its composition: all members are students from multiple universities and schools of Nantes. It is a voluntary choice done by the steering committee. This innovative approach has led the project to a lack of precise specifications; objective is to unleash the imagination and increase the creativity of the team. Consequently, obtained results are really original and would perhaps have never been found in other circumstances, for example by professionals specialized in museographic business!
Consequently the museum will enrich its know-how; and the students are offered the possibility practicing academic achievement thanks to a real and ambitious project.

So as to succeed the project, an active collaboration has been initiated between the Ecole Centrale de Nantes, Ecole Polytechnique de Nantes and the University of Nantes (Department history / art history). This melting was facilitated by the presence of teachers shared between those different domains as shown by figure 9 . Moreover, notice that all teachers belong to various Nantes laboratories that are complementary (IRCCyN, CFV, LINA, IRSTV, CERMA...)

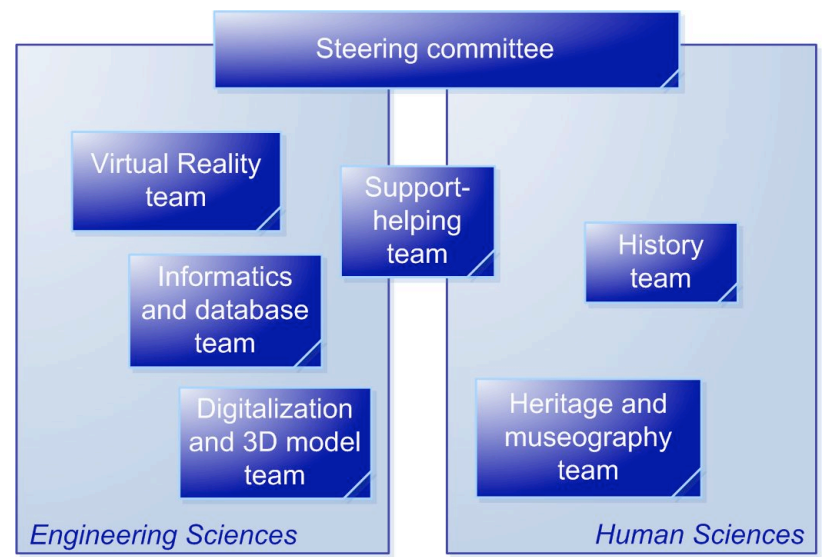

Figure 9: Simplified organisation of Nantes1900 project

Nantes1900 project uses a collaborative platform for working (Team Work Place of Lotus). This tool, connected to a server, allows everyone to access documents uploaded by other members. Team Work Place also includes a manager planning to facilitate the establishment of meetings and main steps of the project. Finally, the use of a collaborative virtual tool provides full traceability of the process in order to capitalize on this experience.

The project is divided into several phases. Each team is involved into one or more tasks. Below are summaries of each task done by students. Notice that they emphasize skills used and acquired.

\section{D digitalization and mock-up}

Objectives. Take a 3D picture of the physical mock-up in order to "immortalize" it. Indeed, there were many objectives to make a $3 \mathrm{D}$ digitalization of the heritage object:

- To preserve it as a virtual copy in case of a potential damage,

- To become a new artefact (see first part of this article about intermediary representation object) that will be used by professionals of heritage domain; such as historian that can study the object directly on their laptop

- To be an intermediary representation and to capture 3D information in case of a 3D design into a virtual world 
Moreover, as it was impossible to move the physical mock-up or to close the museum room, the challenge was to realize the 3D digitalization inside the museum with the public. As it is a pedagogical project, it was another objective to let the visitor discover new technologies and how students manipulate it. For seeing them in action, look at the television reports by taping the keyword "nantes 1900" in www.dailymotion.com

Method. We use a new technology: the Handyscan from the Company Creaform (www.creaform3d.com). Based on a Canadian patent, this tool allows digitalizing an object for obtaining a cloud of points. The scanner is selfpositioned in $3 \mathrm{D}$ space thanks to reflecting targets. It is possible to scan many times the same point for optimizing its position. This technique is without contact and cannot destroy the object, as the laser emitted is visible by human. Moreover, we had the constraint that turning around or going above it was very difficult. Consequently, as Handyscan is handled, it allows user to position it where he wants.

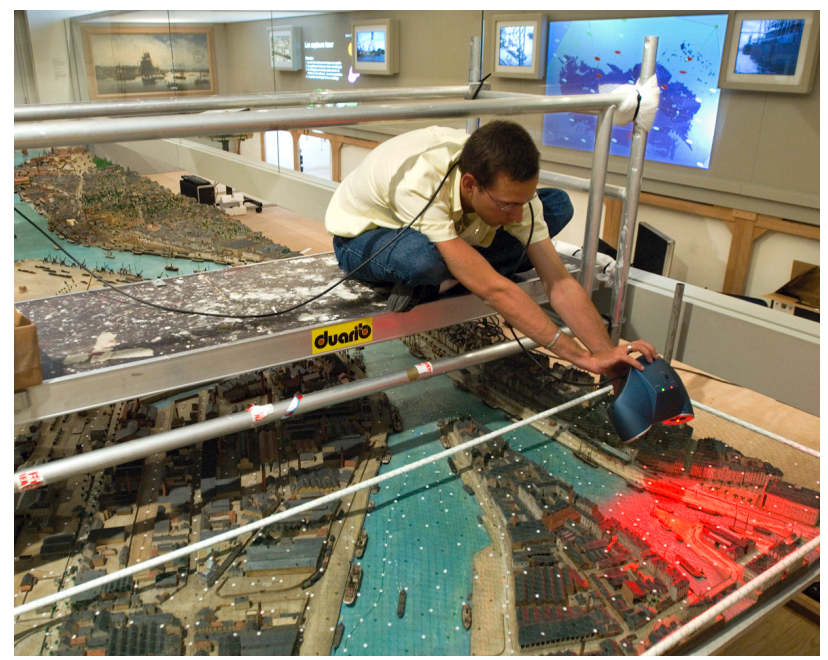

Figure 13: 3D digitalisation inside the museum

\section{Deliverable and assessment:}

- 2 scanners used

- 23 days

- $\quad$ Approximately 3 persons per day

- 174 sessions of STL files

- 4000 photography's for informing cloud of points

- 96000000 points

- $2 / 3$ of the mock-up has been digitalized (as scanner have crashed); new step will begin in June 2010

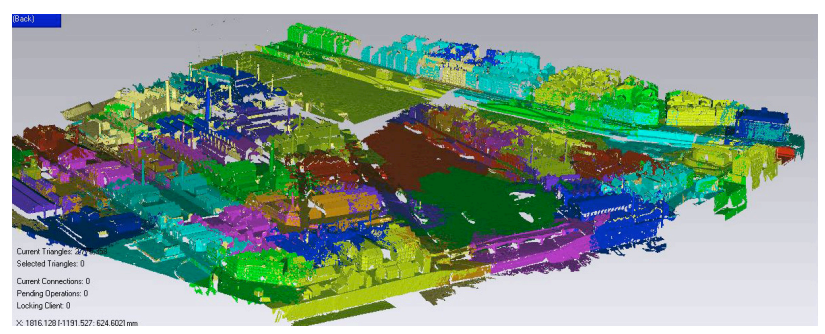

Figure 14: Extract view of the 3D digitalisation

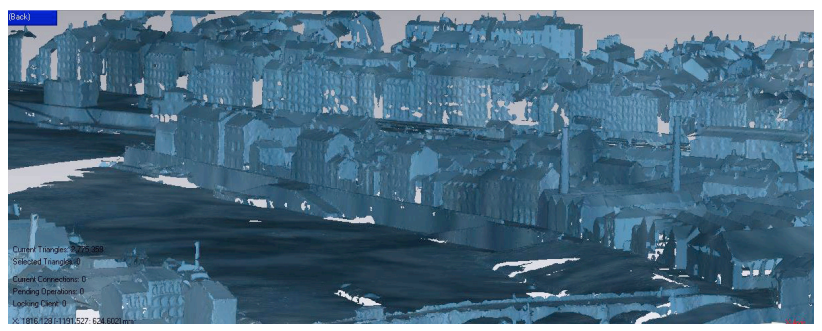

Figure 14b: Extract view of the 3D digitalisation

Considering that the mock-up is at the scale $1 / 500$ it means that a human measures approximately $3 \mathrm{~mm}$ inside the physical mock-up. Notice that the precision is $0.53 \mathrm{~mm}$; that means the virtual model contains one point each $265 \mathrm{~mm}$. Such resolution is said incredible by mathematician or geographical people specialized in GIS (Geographical Information System). Indeed, that means that we obtain a 3D model at $26 \mathrm{~cm}$ precision but at the scale of a city!

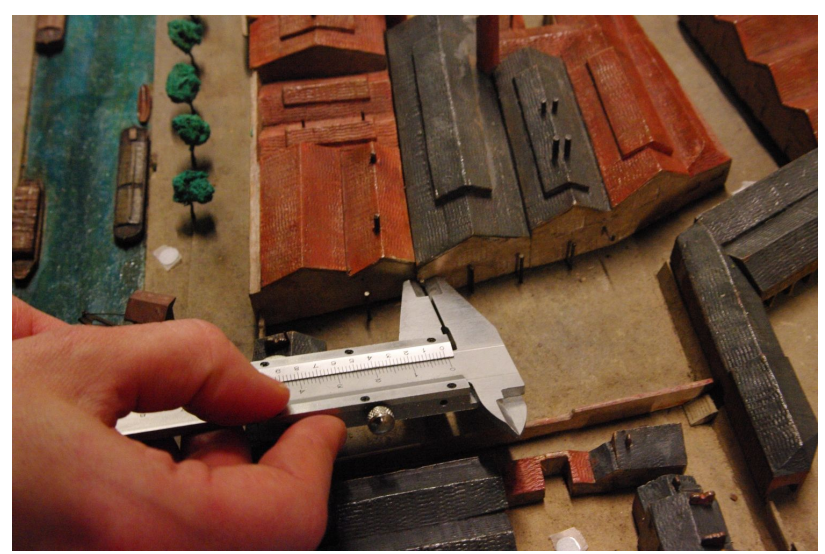

Figure 15: Slide callipers demonstrating the littlest of the mock-up

Colorization / texturing a cloud of points. After the digitalisation, we have only the cloud of points, without any colour. To improve the reality of the digitalized model, we had to put some colours or textures on it. After a big state of the art, we decided to try our own method: use the normal of the points for colorizing.

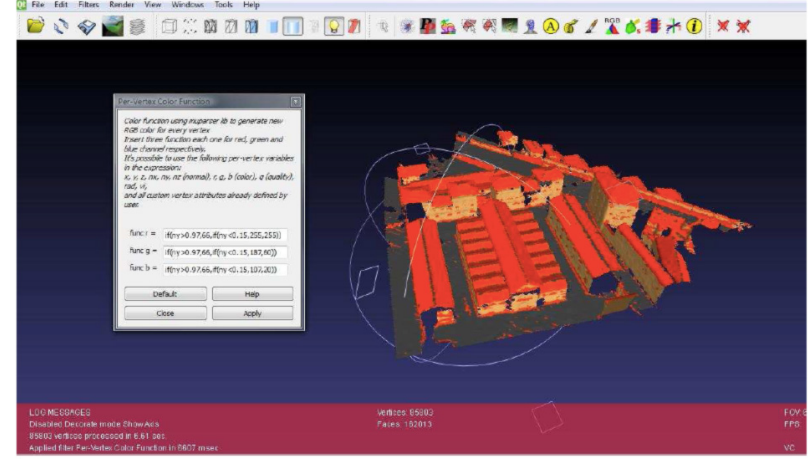

Figure 16: First experimentation of 3D colorization

Indeed, the ground has vertical normal, wall horizontal normal and other vertical by default are roof. Firstly, we segmented the cloud of points with an algorithm similar to Rabbani \& al [9], in many plans, considering that wall, roof and ground have similar normals. Moreover, with a building model, we can have specifics characteristics and 
thus we used $\mathrm{Pu} \&$ al method [10]. It allows fractionise the town into buildings, and each building into roof, ground and wall. With this method, we have a first realistic view of a coloured model. Moreover, this segmentation can help historians to better understand the model and search specific information's.

\section{D mesh simplification}

General objectives. Files obtained by the digitalisation cannot be manipulated in an easy way as they are too heavy. Indeed, the entire file is constituted of 96 million points and there is no current system able to open it and to make a preview. That's objective of this team is to develop a method and a tool for decimating automatically numerous scanned files.

Deliverables. We had obtained a decimation method for 3D files and we have programmed it in $\mathrm{C}++$; it can also be implemented in OpenMesh. Moreover we simplify the 3D model to a $2 \mathrm{D}$ vectorized model that can be used in GIS (Geographical Information System).

Personal profits. Belonging to informatics' domain, this project allows us to discover heritage and museographic domains. Work on new technologies as digitalization. Learning how to structure and manipulate $3 \mathrm{D}$ data. Project management in autonomy and in connection with the other teams project.

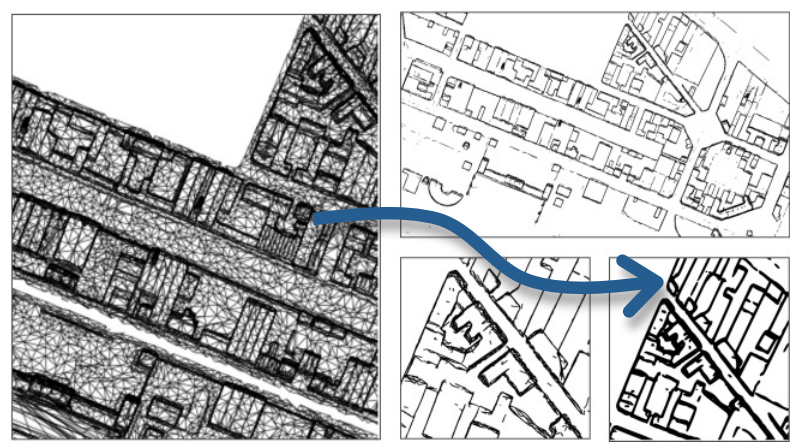

Figure 17: $3 \mathrm{D}$ decimation: $5 \%$ reduction to $2 \mathrm{D}$ file

\section{History team}

General objective. The purpose of the group History / Heritage in Nantes 1900 project is to document the artefact and thus "feed" the database. This is the common work of historians (records and literature researches).

Deliverables. The team had two forms of deliverables: firstly, the documentation of the model and its database thanks to studies of heritage records. This work is like a picture of the mock-up with thousand references. Secondly, it was not really a deliverable but more a support to other groups: for improving understanding between the two worlds: the technicians and historians (understand the relationship between an historian, a scientific history subject, a curator, a visitor and the enhancement tool).

Skills acquired. During the project, the history team has learned a lot especially in terms of confrontation with members from technology domains. The meeting between those two worlds has been particularly enriching. The project was an opportunity to familiarize historians with the construction of database, 3D scanning with a handheld scanner...

Personal benefits. The Nantes 1900 project was an opportunity to participate in a scientific research project and advanced technology gathering partners from different fields of study. In addition, this project was aimed at a famous museum, especially facing the use of new technologies for cultural mediation.

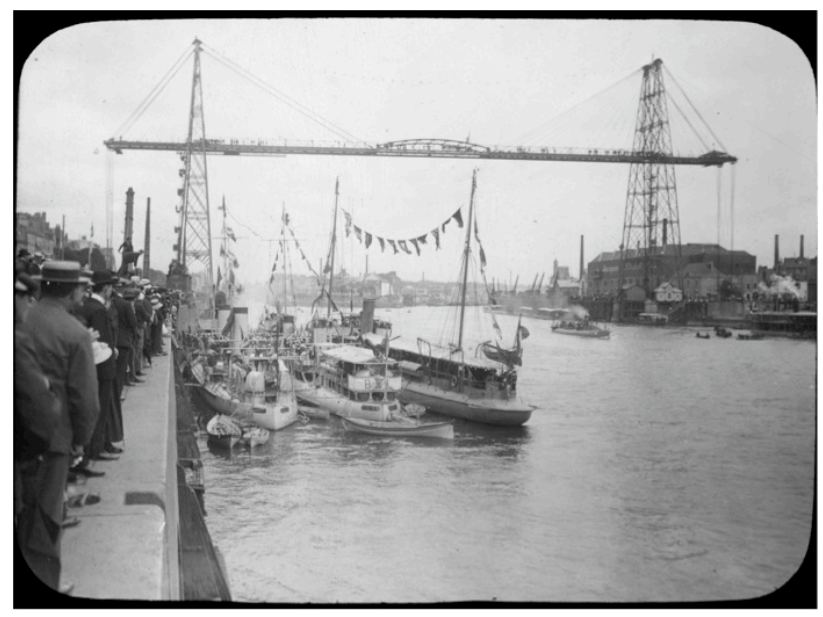

Figure 10: Historical records: Nantes Harbour in 1900

\section{Informatics and database team}

Aims. Create a scalable database storing the geolocalized 3D model and a big amount of indexed heterogeneous documents. Moreover, we have to develop a search engine linked to the content of the database. So as to, a UML model has been developed. It is an operating view of the DHRM. First of all a state of the art of similar project have been done. Many heritage database have been found about digital libraries, digital humanities [11] as Gallica, CNUM, Mérimée... with associated projects as Rome reborn [12] [13] [14] [15], Prague mock-up [16]... The powerful of our model is that it is "intelligent" as it will automatically create and adapt its structure when new categories of elements will be entered (by non informatics' people).

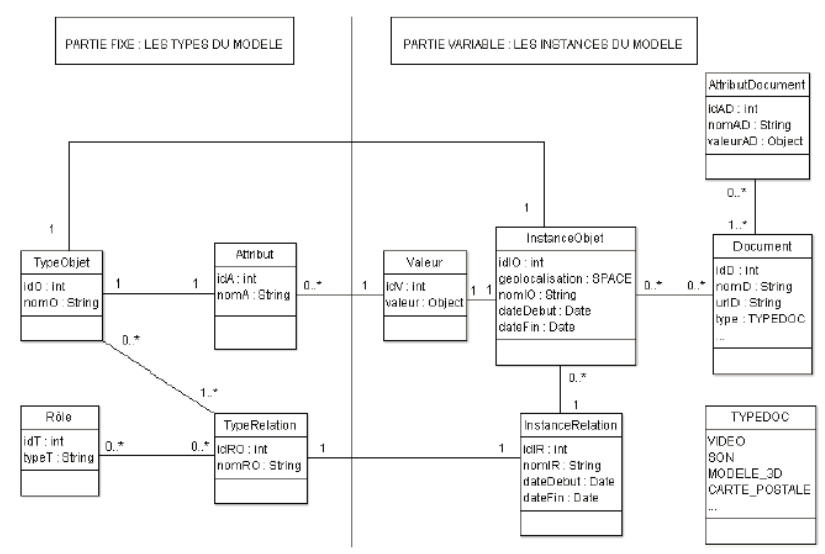

Figure 11: DHRM model for the Nantes1900 project database 
Deliverable. In addition to a fully functional database, the team will provide a web interface (for tests only).

Interfacing with other teams. Main difficulty deals with the ability to provide an interface allowing two independent teams to execute search query (light pointing devices team and multi-touch screen team). Thus, through using localized coordinates from the model, the system returns a list of answers sorted by relevance and split into several categories (main topic, photos, related topics, close places...). Moreover, system will be "intelligent": queries must use semantic entries and not keywords.

Skills and personal benefits. This project represents for our informatics' team an incredible opportunity to contribute to a great museum project. The discussions between historians and computer scientists taught students to adapt their speech in order to be understood by everyone. This project is a real opportunity for students to work with very different kinds of people and to put the knowledge we learned at school into practice.

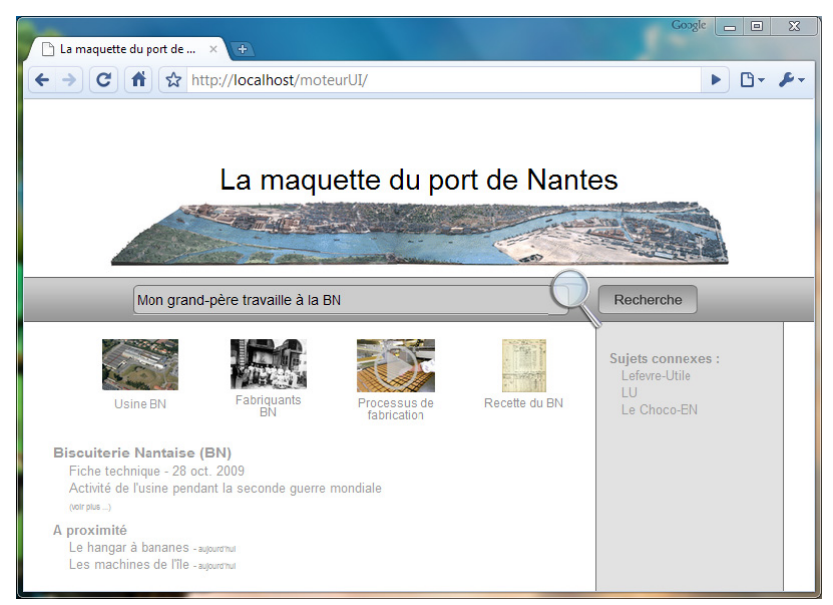

Figure 12: First results of the semantic search engine

\section{Virtual Reality application}

General objectives. This team is in charge to develop an interactive pointing device coupled to a tactile screen and a 3D stereoscopic screen. One of the success keys consists to achieve a pointing device allowing to link the physical object and its digital representation. Visitors will be able to see the virtual view thanks to interactive terminals as show by figure 7 .

Deliverable. It will be a prototype of an operating pointing device. This prototype will be constituted of a projector light dimensioned according to the constraint of the nondestruction of the physical mock-up. Developed software will control the projector thanks to an electronic interface.

Interfacing with other teams. The pointing device must be able to retrieve and process data location to a light point on the physical mock-up. Obviously queries done by visitors on the tactile screen will also returns results directly on the same tactile screen. In addition, the 3D screen placed in front of the visitor will give him more information as for example a $3 D$ sketch or the $3 D$ cloud points of the buildings or blocks he is studying.

Personal Benefits. Working with people with training and owning varied experiences is very rich. Further work on a subject of such history allows students to learn more about the history of Nantes.

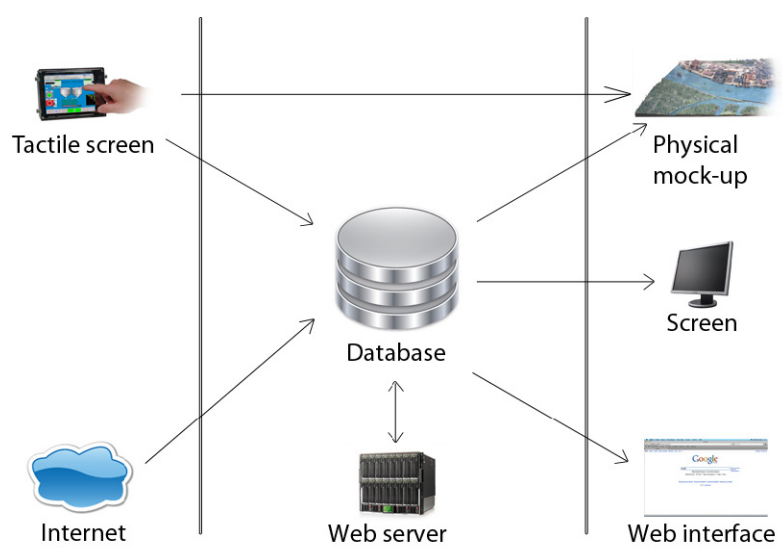

Figure 18: Functional diagram

\subsection{Conclusion}

One of the particularities of Nantes 1900 project is linked to its strong interdisciplinary.

As a conclusion, we can say that at the beginning of the project there is only an old object aged more than 100 years old. But more than 60 persons among students, teachers, researchers and professionals have been and are still working for this study.

Obviously they are not only students from engineering schools or historical department; sooner, students in geography will join them. The Nantes 1900 project requires several domain of excellence. Each student brings the methods and practices of his expertise and its specific knowledge. This is the basis for interdisciplinary. Interdisciplinary facilitates discovery of other university courses offered in Nantes.

Interdisciplinary also results in comparing the different methodologies from involved disciplines. Most of the time processes are different. Indeed, interdisciplinary create a synergy which is very beneficial and indispensable for succeeding the project. Various fields took alone could not drive it; mixing new disciplines is a new kind of design process where keywords are not power but culture and knowledge.

\section{ACKNOWLEDGMENT}

Project management is trusted by a Steering Committee composed jointly by:

- Bertrand Guillet - Conservative Director of the History Museum of Nantes,

- Christophe Courtin - Head of Multimedia department of the History Museum of Nantes,

- Jean-Louis Kerouanton - teacher-researcher University of Nantes, UFR Sciences et Techniques and member of the laboratory Centre Francois Viète (EA CNRS 1161),

- Florent Laroche - teacher-researcher at Ecole Centrale de Nantes, Laboratory IRCCyN Institute for Research in Communication and Cybernetics of Nantes (UMR CRNS 6597).

We also would like to thank students that has participated or which are still active in the project:

- At Ecole Centrale de Nantes: Didier Serveille, Clotilde Marie d'Avignon, Aurore Tarrisse, Arthur Bonnet, Henri Der Sarkissian, Charlène Fleury, 
Guillaume Goguelin, Cédric Télégone, Marc Tremsal, Charles Croz, Natacha Javalet, Ellena Le Breton, Dimitri Moreau, Felipe Benincasa, Antoine Filhol, Audrey Devisscher, Vitaly Kosyrev

- At Nantes University Department of history: Jérémy Boschel, Grégoire Onillon, Anne Guiguin

- At Polytech'Nantes: Mehdi Bouayad, Clément Gaschet, Benoit Hervé, François Sarrazin, Imad Zidane, Tayib Faraj, Omar Mimet, Marie-Elise Lecoq, Peter Adib, François Perez, Lucie Thourault, Julsonne Gandon, Maëlle Autretr, Halvard Douaud, Younes Ennajjar, Feifei Jing

Special thanks to our team of teachers and researchers: Fabien Picarougne, Guillaume Raschia, Myriam Servières, Guillaume Moreau, Eric Friot, Vincent Gouret, Philippe Depince, Alain Bernard, Abdelhamid Chriette, Corentin L'hostis, Fabrice Brau, Stéphane Tirard.

We also would like to thanks for their help during the $3 D$ digitalization phase: Gaelle Corbin, Eva Dayot, Noel Biton and all the staff of the Museum.

\section{REFERENCES}

[1] A. Bernard, F. Laroche, S. Ammar-Khodja, N. Perry, 2007, "Impact of new 3D numerical devices and environments on redesign and valorisation of mechanical systems", CIRP Annals - Manufacturing Technology, Vol. 56/1/2007, ISSN 0007-8506, pp.143148

[2] J.-P. Houdin, 2007, "3D Unveils the mystery of the great pyramid", http://www.3ds.com/introduction, web site seen the $3^{\text {rd }}$ of March 2007

[3] F. Laroche, A. Bernard, M. Cotte, 2006, "Between heritage and Industrial Engineering, a new life for old product: virtuality", revue Research in Interactive Design, Vol.2, 7 p., Ed. Springer, ISBN 2-287-48363-2

[4] F. Laroche, A. Bernard, M. Cotte, 2008, "Virtualization of ancient technical objects: a new design process and its inter-disciplinary team", CIRP Design conference Seminar, Twente University, 6 p.
[5] A. Bernard, S. Ammar-Khodja, N. Perry, F. Laroche, 2007, "Virtual engineering based on knowledge integration", Journal Virtual and Physical Prototyping, Vol. 2, n³, Taylor \& Francis, ISSN 1745-2767, pp.137154

[6] F. Laroche, A. Bernard, M. Cotte, 2008, "Advanced Industrial Archaeology: A new reverse-engineering process for contextualizing and digitizing ancient technical objects", Journal Virtual and Physical Prototyping, Vol. 3, $\mathrm{n}^{\circ} 2$, Taylor \& Francis, ISSN 17452759, pp.105-122

[7] W. Derigent, S. Remy, E. Chapotot, G. Ris, A. Bernard, 2007, "3D digitising strategy planning approach based on CAD model", Transactions of the ASME, Journal of Computing and Information Science In Engineering, vol. 7, $\mathrm{n}^{\circ}$, pp 10-19

[8] B. Guillet, Bertrand, L. Huron, J.-L. Kerouanton, 2001, "La maquette du Port de Nantes", French congress Des villes, des ports : la mer, les hommes ( ${ }^{\circ} 124$; 1999; Nantes), Paris, CTHS Editions, pp. 143-155.

[9] S. Pouyllau, 2008, "Digital humanities en France : le temps des pionniers", http:// blog. stephanepouyllau. org/digital-humanities-en-france-le-temps-despionniers/

[10] The Institute for Advanced Technology in the Humanities, 2009, "Rome reborn", http: // www. romereborn. virginia. edu/

[11] Google, 2009, "Google sketchup 7", Technical report, Google

[12] P. Fleury, 1997, "La rome antique sur l'internet", Informatics and statistics review for human sciences

[13] Université de Caen Basse Normandie, 2009, "Rome city map - objectives", http: // www. unicaen. fr/ services/ cireve/ rome/ pdr_ restitution. php? fichier= objectifs

[14] D. Langweil, 2008, "Digitalization of Prague city, last step", http://www.praguemodels.cz/

[15] T. Rabbani, F. A. van denHeuvel, G. Vosselman, 2006, "Segmentation of points clouds using smoothness constraint"

[16] S. Pu, G. Vosselman, 2006, "Automatic extraction of building features from terrestrial laser scanning" 